\title{
Geant4 calculations for space radiation shielding material $\mathrm{Al}_{2} \mathrm{O}_{3}$
}

\author{
Veli Capali1,a, Tolga Acar Yesil ${ }^{2}$, Gokhan Kaya ${ }^{2}$, Abdullah Kaplan ${ }^{1}$, Mustafa Yavuz ${ }^{2}$ and Tahir Tilki ${ }^{2}$ \\ ${ }^{1}$ Süleyman Demirel University, Faculty of Arts and Sciences, Department of Physics, 32260 Isparta, Turkey \\ ${ }^{2}$ Süleyman Demirel University, Faculty of Arts and Sciences, Department of Chemistry, 32260 Isparta, Turkey
}

\begin{abstract}
Aluminium Oxide, $\mathrm{Al}_{2} \mathrm{O}_{3}$ is the most widely used material in the engineering applications. It is significant aluminium metal, because of its hardness and as a refractory material owing to its high melting point. This material has several engineering applications in diverse fields such as, ballistic armour systems, wear components, electrical and electronic substrates, automotive parts, components for electric industry and aero-engine. As well, it is used as a dosimeter for radiation protection and therapy applications for its optically stimulated luminescence properties. In this study, stopping powers and penetrating distances have been calculated for the alpha, proton, electron and gamma particles in space radiation shielding material $\mathrm{Al}_{2} \mathrm{O}_{3}$ for incident energies $1 \mathrm{keV}-1 \mathrm{GeV}$ using GEANT4 calculation code.
\end{abstract}

\section{Introduction}

Aluminium Oxide, $\mathrm{Al}_{2} \mathrm{O}_{3}$ is the most widely used material in the engineering applications. It is significant aluminium metal, because of its hardness and as a refractory material owing to its high melting point. It is one of the most important materials due to its interesting characteristics such as easy availability, low cost, low environmental impact, ease of synthesis, good optical transparency, high refractive index, high melting point, hydrophobicity, mechanical strength, dielectric behaviour, electrical insulating property, thermal, and chemical stability [1].

NASA has always had a major emphasis on developing technologies that can be used for manned space flight, space station and satellite. Clearly, any sort of manned space requires extraordinary design considerations and extremely effective technology, because there are innumerable hazards associated with manned space flight [2]. Among these, radiation damage and heat and cold thermal efficient are very major concern. Currently, NASA uses aluminium for radiation shielding [3].

This material is marginally effective at radiation shielding, since it has a low electron density. Therefore, researchers have been looking for other materials, which have higher hydrogen content than aluminium, to use as radiation shielding material. It would then re-enter the atmosphere of the Earth and glide back down to the ground. In order to withstand the high temperatures associated with re-entry, NASA created the Space Shuttle Orbiter Thermal Protection System (TPS) [4].

\section{Methods}

GEANT4 is a free simulation and calculation code that can be used to investigation of high-energy physics, medical physics, space, and radiation physics. GEANT4 is an abundant set of physics models to handle the interactions of particles with matter across a large energy range. Data and expertise have been drawn from many sources around the world and in this respect, GEANT4 acts as a repository that incorporates a large part of all that is known about particle interactions [5].

Energy lost by $\alpha$-particle in a single collision is very small. However the energy gained by the orbiting electron is often more than the binding energy of the atom and is therefore removed from the atom. The interacting atom is said to be ionized due to this $\alpha$-particle electron collision. The physical quantity that describes the slowing down of charged particles in mater is the stopping power $\mathrm{dE} / \mathrm{dx}$ where $\mathrm{dE}$ is the energy lost in the distance $\mathrm{dx}$. The Bohr relation for stopping power of heavy particle is given by

$$
-\frac{d E}{d x}=\frac{4 \pi z^{2} k_{0}^{2} e^{4}}{m v^{2}} \ln \left(\frac{2 m v^{2}}{I}\right)
$$

$\mathrm{n}=$ number of electrons per unit volume,

$\mathrm{m}=$ electron rest mass,

$\mathrm{v}=$ velocity of the particle,

$\mathrm{Z}=$ charge of the particle,

$\mathrm{e}=$ electron charge

$\mathrm{k}_{\mathrm{o}}=1 / 4 \pi \varepsilon_{0}$,

$\mathrm{I}=$ mean excitation energy of the medium [6].

This was modified by taking into account the quantum effects by Bethe, and the relativistic effects by Bloch, and finally the well-known Bethe-Bloch expression for the stopping power was given as [7]:

$$
-\frac{d E}{d x}=\frac{4 \pi z^{2} k_{0}^{2} e^{4}}{m v^{2}}\left[\ln \left(\frac{2 m v^{2}}{I}\right)-\ln \left(1-\frac{v^{2}}{c^{2}}\right)-\frac{v^{2}}{c^{2}}\right]
$$

\footnotetext{
${ }^{a}$ Corresponding author: velicapali@sdu.edu.tr
} 
The stopping power given in the above equation takes into account only collisions with electrons. Events with nuclei are not considered in this formula. There is one important drawback of this formula. It was derived using the perturbation theory and the first Born approximation [8].

\section{Results}

The penetrating distance and stopping power calculations of alpha, electron, proton and gamma particles for $\mathrm{Al}_{2} \mathrm{O}_{3}$ shielding material have been given in Figs. 1 and 2. The calculated stopping power values of alpha, proton and electron projectile particles in $\mathrm{Al}_{2} \mathrm{O}_{3}$ target for incident energies of $1 \mathrm{keV}-1 \mathrm{GeV}$ have been exhibited in Fig. 1. Based on an approximate theory i.e. the Thomas Fermi model of atom, Bohr suggested that for high energies above $100 \mathrm{keV}$ region, the stopping power decreases as the particle velocity approaches the velocity of light. When the velocity of the particle is comparable with speed of light, the normal spherical field becomes distorted in the direction of motion of the particle expanding laterally and in the perpendicular direction shrinking. Bethe Bloch suggested that for high energies above approximately 1 $\mathrm{MeV}$ region, the stopping power decreases as the incident particle's energy.

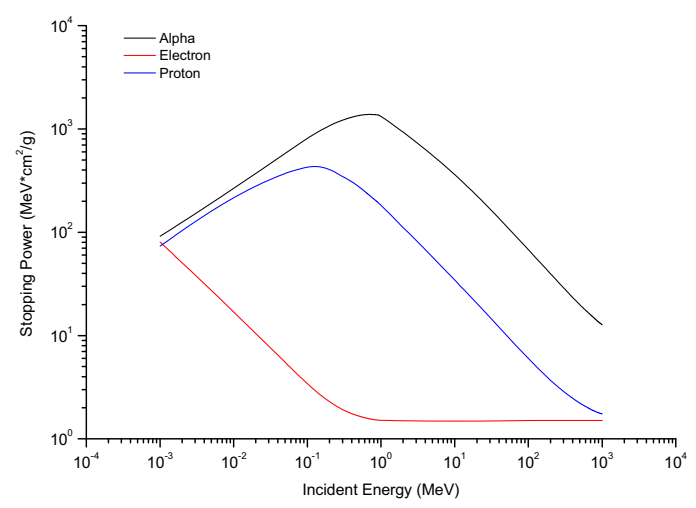

Figure 1. The stopping power calculations of proton, electron and alpha particles in the incident energy range of $1 \mathrm{keV}-1 \mathrm{GeV}$ for $\mathrm{Al}_{2} \mathrm{O}_{3}$.

The penetrating distance calculations of alpha, electron, proton and gamma particles for $\mathrm{Al}_{2} \mathrm{O}_{3}$ shielding material have been given in Figs. 2 and 3. According to calculated penetrating results, the penetrating distance of alpha particles are the poorest. So this particles cannot be managed to enter into $\mathrm{Al}_{2} \mathrm{O}_{3}$. On the contrary alpha particles, gamma has the most penetrating in the $\mathrm{Al}_{2} \mathrm{O}_{3}$ target.

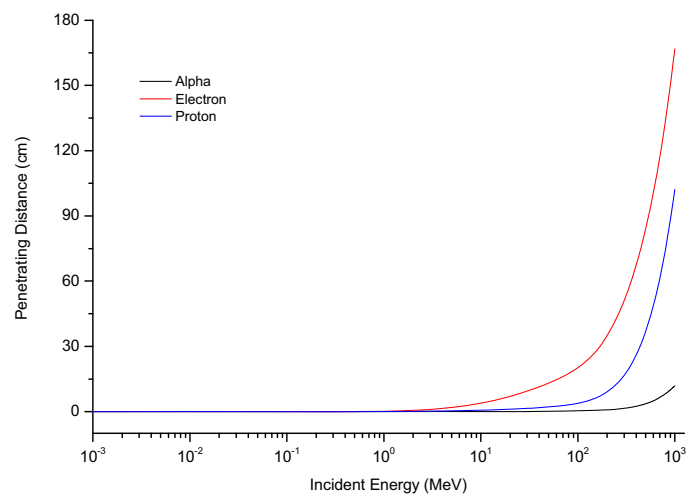

Figure 2. The penetrating distance calculations of proton, electron and alpha particles in the incident energy range of $1 \mathrm{keV}$ $-1 \mathrm{GeV}$ for $\mathrm{Al}_{2} \mathrm{O}_{3}$.

In the incident gamma energy range of $1 \mathrm{keV}-0,9$ $\mathrm{MeV}$, required stopping thickness of $\mathrm{Al}_{2} \mathrm{O}_{3}$ could be approximately $1,7 \mathrm{~cm}$.

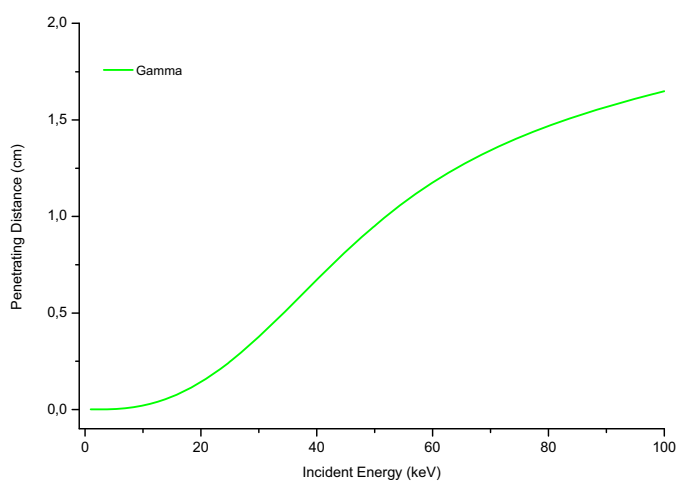

Figure 3. The penetrating distance calculations of gamma in the incident energy range of $1 \mathrm{keV}-100 \mathrm{keV}$ for $\mathrm{Al}_{2} \mathrm{O}_{3}$.

All calculated stopping power and penetrating distance results used by GEANT4 have been given in Tables 1, 2 and 3.

Table 1. The Geant4 penetrating calculations results of proton, electron and alpha particles for $\mathrm{Al}_{2} \mathrm{O}_{3}$.

\begin{tabular}{|c|c|c|c|}
\hline $\begin{array}{c}\text { Energy } \\
(\mathrm{MeV})\end{array}$ & $\begin{array}{c}\text { Alpha } \\
\text { Penetrating } \\
\text { Distance } \\
(\mathrm{cm})\end{array}$ & $\begin{array}{c}\text { Electron } \\
\text { Penetrating } \\
\text { Distance }(\mathrm{cm})\end{array}$ & $\begin{array}{c}\text { Proton } \\
\text { Penetrating } \\
\text { Distance } \\
(\mathrm{cm})\end{array}$ \\
\hline 0.001 & $1.76 \mathrm{E}-05$ & $2.29 \mathrm{E}-05$ & $6.85 \mathrm{E}-05$ \\
\hline 0.01 & $2.30 \mathrm{E}-04$ & $4.98 \mathrm{E}-04$ & $2.17 \mathrm{E}-04$ \\
\hline 0.1 & $4.30 \mathrm{E}-04$ & 0.00453 & $7.84 \mathrm{E}-04$ \\
\hline 0.2 & $6.80 \mathrm{E}-04$ & 0.01409 & 0.00135 \\
\hline 0.3 & $8.42 \mathrm{E}-04$ & 0.02632 & 0.00201 \\
\hline 0.4 & $9.81 \mathrm{E}-04$ & 0.04012 & 0.00277 \\
\hline 0.5 & 0.00111 & 0.0549 & 0.00363 \\
\hline 0.6 & 0.00168 & 0.07033 & 0.00459 \\
\hline 0.7 & 0.00193 & 0.08622 & 0.00565 \\
\hline 0.8 & 0.0021 & 0.10246 & 0.0068 \\
\hline 0.9 & 0.00234 & 0.11895 & 0.00805 \\
\hline
\end{tabular}




\begin{tabular}{|c|c|c|c|}
\hline 1 & 0.0024 & 0.13561 & 0.00938 \\
\hline 10 & 0.05271 & 1.68422 & 0.40925 \\
\hline 100 & 0.20755 & 16.8012 & 2.42436 \\
\hline 200 & 0.71304 & 33.4877 & 8.0816 \\
\hline 300 & 1.46686 & 50.159 & 15.9504 \\
\hline 400 & 2.43978 & 66.8267 & 25.4686 \\
\hline 500 & 3.60954 & 83.4936 & 36.2854 \\
\hline 600 & 4.95783 & 100.16 & 48.1289 \\
\hline 700 & 6.46885 & 116.27 & 60.7857 \\
\hline 800 & 8.12877 & 133.494 & 74.0742 \\
\hline 900 & 9.92531 & 150.16 & 87.8831 \\
\hline 1000 & 11.8485 & 166.827 & 102.132 \\
\hline
\end{tabular}

Table 3. The Geant4 stopping power calculations results of gamma particles for $\mathrm{Al}_{2} \mathrm{O}_{3}$.

\begin{tabular}{|c|c|}
\hline $\begin{array}{c}\text { Energy } \\
(\mathrm{MeV})\end{array}$ & $\begin{array}{c}\text { Gamma Penetrating Distance } \\
(\mathrm{cm})\end{array}$ \\
\hline 0.001 & $8.92 \mathrm{E}-04$ \\
\hline 0.01 & 0.00158 \\
\hline 0.1 & 0.12273 \\
\hline 0.2 & 0.36485 \\
\hline 0.3 & 0.67607 \\
\hline 0.4 & 0.96181 \\
\hline 0.5 & 1.18423 \\
\hline 0.6 & 1.34936 \\
\hline 0.7 & 1.4734 \\
\hline 0.8 & 1.57004 \\
\hline 0.9 & 1.64883 \\
\hline
\end{tabular}

proton, electron and alpha particles for $\mathrm{Al}_{2} \mathrm{O}_{3}$.

\begin{tabular}{|c|c|c|c|}
\hline $\begin{array}{l}\text { Energy } \\
(\mathrm{MeV})\end{array}$ & $\begin{array}{c}\text { Alpha } \\
\text { Stopping } \\
\text { Power } \\
\left(\mathrm{MeV}^{*} \mathrm{~cm} 2 / \mathrm{g}\right) \\
\end{array}$ & $\begin{array}{c}\text { Electron } \\
\text { Stopping } \\
\text { Power } \\
\left(\mathrm{MeV}^{*} \mathrm{~cm} 2 / \mathrm{g}\right) \\
\end{array}$ & $\begin{array}{c}\text { Proton } \\
\text { Stopping } \\
\text { Power } \\
\left(\mathrm{MeV}^{*} \mathrm{~cm} 2 / \mathrm{g}\right) \\
\end{array}$ \\
\hline 0.001 & 91.7138 & 80.3267 & 73.51 \\
\hline 0.01 & 260.744 & 17.3191 & 232.5 \\
\hline 0.1 & 828.899 & 3.30542 & 470 \\
\hline 0.2 & 1083.77 & 2.26224 & 412.7 \\
\hline 0.3 & 1222.91 & 1.91587 & 345.5 \\
\hline 0.4 & 1306.44 & 1.7528 & 310.6 \\
\hline 0.5 & 1355.2 & 1.66384 & 276.5 \\
\hline 0.6 & 1379.95 & 1.60608 & 249.4 \\
\hline 0.7 & 1386.82 & 1.56534 & 227.9 \\
\hline 0.8 & 1382.69 & 1.53815 & 210.2 \\
\hline 0.9 & 1371.6 & 1.519 & 195.7 \\
\hline 1 & 1353.52 & 1.50706 & 183.2 \\
\hline 10 & 394.568 & 1.47181 & 35.309 \\
\hline 100 & 68.2801 & 1.507 & 5.895 \\
\hline 200 & 39.6243 & 1.51054 & 3.659 \\
\hline 300 & 29.0284 & 1.51115 & 2.877 \\
\hline 400 & 23.4376 & 1.5113 & 2.464 \\
\hline 500 & 19.9658 & 1.51133 & 2.214 \\
\hline 600 & 17.5955 & 1.51133 & 2.051 \\
\hline 700 & 15.8731 & 1.51133 & 1.938 \\
\hline 800 & 14.565 & 1.51133 & 1.855 \\
\hline 900 & 13.5382 & 1.51133 & 1.793 \\
\hline 1000 & 12.7116 & 1.51133 & 1.745 \\
\hline
\end{tabular}

Composite materials that contain the highest hydrogen and oxygen are very good shielding materials whereas aluminium and same materials are not a good shielding material due to its low electron density [5]. Therefore, $\mathrm{Al}_{2} \mathrm{O}_{3}$ is better than aluminium for radiation shielding. In the incident alpha, electron and proton energy range of 1 $\mathrm{keV}-1 \mathrm{GeV}$, required stopping thickness of $\mathrm{Al}_{2} \mathrm{O}_{3}$ could be approximately $12,167,103 \mathrm{~cm}$. respectively. The obtained $\mathrm{Al}_{2} \mathrm{O}_{3}$ stopping power results for the projectile charged particles can be used in several applications such as space engineering, radiation therapy and protection.

\section{References}

1. R.K. Sharma, P. Jeevanandam, Ceramics International, 39, 3337 (2013)

2. J.W. Wilson, J. Miller, A. Konradi, F.A. Cucinotta, NASA Conference Publication vii, 3360 (1997)

3. http://www.nasa.gov/vision/space/travelinginspace/ra diation_shielding.html.

4. http://www.nasa.gov/centers/ames/research/humanin space/humansinspace-thermalprotectionsystem.html

5. S. Agostinelli, et al., Nucl. Instrum. Methods Phys. Res. A. 506, 250 (2003)

6. M. Inokuti, Rev. Mod. Phys. 43, 297 (1971)

7. H. Bethe, Ann. Phys. 5, 325 (1930)

8. A. Getachew, "Stopping power and range of Protons of various energies in Different materials", Depart. of Physics, Addis Ababa University (2007) 